Fisheries Research

June 2017, Volume 190 Pages 132-139

http://dx.doi.org/10.1016/i.fishres.2017.02.005

http://archimer.ifremer.fr/doc/00373/48415/

(c) 2017 Elsevier B.V. All rights reserved.

\title{
Utility of mixed effects models to inform the stock structure of whiting in the Northeast Atlantic Ocean
}

\author{
Barrios Alexander ${ }^{1}$, Ernande Bruno ${ }^{2}$, Mahé Kelig ${ }^{2}$, Trenkel Verena ${ }^{1}$, Rochet Marie-Joelle ${ }^{1, *}$ \\ ${ }^{1}$ Ifremer, rue de l'lle d'Yeu, Nantes, France \\ ${ }^{2}$ Ifremer, 150 quai Gambetta, Boulogne-sur-Mer, France \\ * Corresponding author : Marie-Joëlle Rochet, email address : $\underline{\text { mjrochet@ifremer.fr }}$
}

\begin{abstract}
:
Stock structure of whiting (Merlangius merlangus) in the North East Atlantic is unclear. This study uses mixed effects models to analyse growth variability as a way to investigate stock identification. Growth trajectories for 634 individuals and length-at-age data for 78,686 individuals were analysed for spatial coherence and temporal synchrony in the parameters of the von Bertalanffy growth model. Growth was found to differ among most ICES divisions, and temporal fluctuations were poorly synchronized between areas. This study illustrates how growth analyses can contribute to stock identification, in addition to other data.
\end{abstract}

\section{Highlights}

- Variability in whiting (Merlangius merlangus) growth in the North East Atlantic was investigated by mixed effects models. Individual growth trajectories 1997-2009 and population length-at-age 20062011 differed between areas. - Time series of growth parameters 1986-2011 differed between two areas of the North Sea. Growth patterns contribute to understand whiting stock structure in this area.

Keywords : Growth, Whiting, North East Atlantic, Otolith, von Bertalanffy growth model, Mixed effects models 


\section{Introduction}

Stock structure of whiting (Merlangius merlangus) in the North East Atlantic is unclear. Biological, stock assessment and fisheries management units do not coincide for whiting (Fig. 1) (Reiss et al., 2009). The general genetic structure of whiting in the area seems to be indistinct, suggesting a single wide-ranging population, except in the North Sea where distinct sub-populations have been reported (Charrier et al., 2007). Meanwhile, the species is assessed by the International Council for the Exploration of the Sea (ICES) as eight separate stocks, one of which includes the North Sea and Eastern English Channel (Reiss et al., 2009). In contrast, the Celtic Sea, Irish Sea and Bay of Biscay are considered separate stock units whereas available genetic evidence suggests they might belong to a single stock, while the North Sea, for which more genetic structure has been reported, is assessed as a single unit. However, genetic analyses are not always sufficient to delineate stock units for management (Lowe and Allendorf, 2010), especially those based on neutral markers (Nielsen et al., 2009), which were used by Charrier et al. (2007). Moreover, the practice of stock identification nowadays relies on multiple multidisciplinary analyses. Further, phenotypic differences can be relevant for management (Cadrin et al., 2014), even if they are hardly detectable using genetic methods (Nielsen et al., 2009).

Life history traits can contribute to identify stock structure, either at an early stage when no other data are available, or to provide context for stock structure dynamics (McBride, 2014). Growth characteristics have been used for a long time to help identify stock structure (e.g., Abaunza et al., 2008; Macdonald et al., 2013; McBride, 2014; Sequeira et al., 2012). Since growth, as other life history traits, is determined by genetics, demographics, and the environment, the responses of population components to environmental drivers can also contribute to delineation of stock units (Heino, 2014; McBride, 2014). Environmental drivers are taken here in a broad sense, as opposed to intrinsic, inherited chararcteristics. For whiting these drivers may include temperature and population density (Baudron et al., 2014; Hunter et al., 2016; Lauerburg et al., 2015).

Calcified structures such as scales or otoliths are often used for ageing fish. Growth at the population level is then analysed from age-length relationships. Moreover, measuring daily or annual growth increments on otoliths allows individual growth trajectories to be reconstructed to better appraise scales of variability (Panfili et al., 2002).

Mixed effects models are increasingly used in fisheries biology (Thorson and Minto, 2015). Recently, they have been applied to analyse growth at various levels and explain variability caused by environmental and/or intrinsic factors (Morrongiello and Thresher, 2015; Shelton et al., 2013; Vincenzi et al., 2014).

Here mixed effects models were used to analyse growth variability of whiting in the North East Atlantic. The main aim was to examine whether this kind of analysis could contribute to stock identification. First, individual growth trajectories for whiting collected in the southern North Sea, the Eastern English Channel, and the Celtic Sea from 2007 to 2015 were analysed. The difference between areas in estimated parameters of the von Bertalanffy growth model was examined as a potential criterion to differentiate stock units. Second, age-length data were gathered for a larger sample of individuals collected in the same areas plus the Bay of Biscay from 1996 to 2015. Again, differences in growth parameters between areas were used to identify spatial units with homogeneous growth characteristics. For the Northern and Central North Sea, for which length of time series was sufficient, time trends in growth parameters and their response to population density and temperature were also examined. 


\section{Materials and methods}

\subsection{Study area and data sources}

Whiting is a small gadoid species living in temperate waters in the north-eastern Atlantic, as well as in the Mediterranean and Black Seas. Juvenile whiting feed on plankton in coastal waters (5-30 m depth), while adults are found down to $200 \mathrm{~m}$ depth, and also eat fish and benthic invertebrates (Pinnegar et al., 2003). Whiting live 10 to 20 years and can reach up to $70 \mathrm{~cm}$ (Cohen et al., 1990). Minimum landing size for whiting in the whole ICES area is 27 $\mathrm{cm}$.

Data analysed in this study were collated from two sources: scientific bottom trawl surveys and market sampling of French landings. Trawl surveys included: the International Bottom Trawl Survey (IBTS) carried out annually in quarter 1 in the North Sea, and in quarter 4 in the Celtic Sea and Bay of Biscay, and the Channel Groundfish French Survey (CGFS) carried out in quarter 3 in the Eastern English Channel. These surveys used a stratified random design. At each station, standard 30' hauls were carried out, and the whole catch was identified and length-measured. For selected species, sex was determined, and individuals were randomly selected from each length-class for otolith extraction (see further details on sampling protocol in ICES, 1996). Landings were sampled year-round from fish auctions covering the main ports where whiting is landed, using a métier-based sampling strategy (Leblond et al., 2008). As for surveys, individuals were randomly sampled stratified by sex and length-class. Market samples provided 0 to $23 \%$ of individual fish data depending on area.

Sagittal otoliths were extracted from the cranial cavity to determine fish age. The right sagittal otolith was embedded in epoxy resin and transverse sections through the core (nucleus) were cut with a precision saw (blade thickness: $0.3 \mathrm{~mm}$ ). Two transverse sections were examined using $\times 50$ magnification connected to a video camera and an image-analysis system (TNPC software, www.tnpc.fr). Yearly growth increments were assumed to consist of an opaque and a translucent band. Age was determined by counting these increments following the internationally agreed method (Easey et al., 2005; Ross and Hüssy, 2013). For a subset of otoliths, the width of annual increments was measured in addition to being counted. From both the survey and landings samples two data sets were prepared: i) individual growth trajectories based on increment widths (see details below and Table S1) and ii) population length-at-age using length- and age-at-capture (Table S2, Figures S1, S2).

Environmental data used to explain variations in growth included annual average water column temperature for the whole area, from the sea surface down to $200 \mathrm{~m}$ depth, as predicted by hydrodynamic simulation models (Huret et al., 2013, see http://marine.copernicus.eu/). Intra-specific competition was described by whiting density averaged over the whole area, estimated from the fish trawl survey IBTS.

\subsection{Data analysis}

Continuous age was calculated based on the number of growth increments plus a fraction of year equal to the date of capture minus estimated date of birth. Dates of birth were set to the spawning peak in each area - 15 January in the Bay of Biscay, 15 March in the Celtic Sea and $1^{\text {st }}$ of March in the English Channel, and 15 May in the North Sea (Carpentier et al., 2009; Gibb et al., 2004; Hehir, 2003; Hislop, 1984; Riley et al., 1986).

For reconstructing individual growth trajectories the relationship between total fish length $L_{t}$ and otolith radius $R_{t}$ at capture age $t$ was modelled by a power function:

(1) $L_{t}=a+b R_{t}^{c}$ where $a, b$, and $c$ are regression coefficients. 
Total length at age $i$ could then be estimated (back-calculated) from measurements of annual otolith radii $R_{i}$ as:

(2) $L_{i}=a+\exp \left[\ln \left(L_{0}-a\right)+\frac{\left[\ln \left(L_{t}-a\right)-\ln \left(L_{t}-a\right)\right] \times\left[\ln R_{i}-\ln R_{0}\right]}{\left[\ln R_{t}-\ln R_{0}\right]}\right]$ (Vigliola et al., 2000)

where length-at-age 0 is $L_{0}=a+b R_{0}^{c}$ and $R_{0}$ is the corresponding otolith radius. $R_{0}=0.0096 \mathrm{~mm}$ was assumed based on information available for sole (Solea solea) (Claireaux, 2013). A sensitivity analysis, with $R_{0}$ varying from 0.0048 to $0.0192 \mathrm{~mm}$, showed that this value provided the best fit for reconstructed length-at-capture (Fig. 2).

Eq 2 assumes allometry rather than isometry between fish and otolith size, thereby addressing a shortcoming of many back-calculation models (Francis, 1990). Individual growth trajectories were reconstructed for individuals caught at $t=6$ years or older; younger fish were not included to allow a good estimation of all growth parameters, including asymptotic length.

Individual growth trajectories and population length-at-age data per cohort were modelled separately by the von Bertalanffy growth model

$$
\begin{gathered}
L_{a}=L_{\infty}\left|1-\exp \left(-k\left(a-t_{0}\right)\right)\right|+\varepsilon_{a} \\
\varepsilon_{a} \sim M\left(0, \sigma^{2}\right)
\end{gathered}
$$

where $a$ is age, $L_{\infty}$ asymptotic length, $k$ growth rate, and $t_{0}$ hypothetic age at length 0 .

The three parameters of this model were estimated by mixed effects models. Models were selected based on the Akaike information criteria (AIC). Separate analyses were carried out for males and females, given the known sexual size dimorphism in this species (Keyl et al., 2015).

The relative importance of individual versus spatial variation in growth indicative of separate stocks was estimated by examining the best model for individual growth trajectories among models with (i) random effects for individual fishes for $L_{\infty}, k$, and $t_{0}$ common to all areas; (ii) random effects for individuals nested in three areas for $L_{\infty}, k$, and $t_{0}$, and iii) same as ii) but with four areas. Thus in case i) asymptotic length for individual $i$ in area $j$ was modelled as $L_{\infty i j}=\bar{L}_{\infty}+d_{i j}$ where $d_{i j} \sim N\left(0, \sigma_{w}^{2}\right)$. In case ii) and iii) the model was $L_{\infty i j}=\bar{L}_{\infty}+e_{j}+d_{i j}$ with $e_{j} \sim N\left(0, \sigma_{b}^{2}\right)$ and $d_{\mathrm{ij}}$ as before.

Spatial variation in growth was also examined by fitting mixed effects models to the population length-at-age data. In this case only random effects $e_{\mathrm{j}}$ for areas were used. At both the individual and population levels, various combinations of ICES divisions based on Fig. 1 were tested as area effects, and the best model was retained. The ICES division grouping of this best model was taken as indication of spatial stock structure.

Potential differences in response to environmental variation among ICES divisions were investigated by estimating growth parameters by cohort within area (fixed effect for cohort nested in ICES division) and comparing the time series of cohort-specific growth parameter estimates. Growth parameter estimates by cohort were further related by linear regression to environmental conditions (water temperature and survey-based whiting density in each ICES division) in the year of birth. A different response of growth to these potential factors of growth variability, that is, a significant interaction between area and a given environmental factor, would suggest different stock units. 
Each analysis was carried out on a subset of the data to ensure a sufficient number of observations for each factor level, and a reasonable balance between the number of observations per level (Table S2).

\section{Results}

\subsection{Length back calculation}

The relationship between total fish length and otolith radius at capture was curvilinear as can be seen from the positive values for $c$ in eq (1), and much more so for males than females (Table 1, Figs 2a, S3). The resulting model provided accurate predictions of total length-atcapture (Fig. 2b). Reconstructed individual growth trajectories showed a wide variability both within and between ICES divisions (Figs 3, S4).

\subsection{Analysis of individual growth trajectories}

Models with individual random effects for all the three parameters were selected as best models for both males and females. All three growth parameters of the von Bertalanffy model (eq. 3) were found to differ between areas; the best fit and most parsimonious model was model ii) with three areas: Celtic Sea, English Channel, and North Sea (Southern and Central North Sea grouped, Table 2). Variability between individuals within these three areas $\left(\sigma_{w}\right)$ was generally of similar magnitude as the variability between areas $\left(\sigma_{b}\right)$ except for $L_{\infty}$ for females, which had larger variability between than within areas (Table 3).

We found no significant difference in individual growth parameters between fish caught in the southern $v s$ central North Sea (Table 2). In contrast, most of fish caught in the English Channel grew faster (larger $k$ ) to a smaller asymptotic size $\left(L_{\infty}\right)$ than those caught in the North Sea. Fish caught in the Celtic Sea generally grew at slower rate and to larger asymptotic size than in the other divisions (Fig. 4). Estimates of $k$ and $t_{0}$ were positively correlated $(\mathrm{R}=0.79$ for females). Estimates of $L_{\infty}$ and $t_{0}$ were negatively correlated ( $\mathrm{R}=-0.49$ for females), and there was a strong, negative correlation ( $\mathrm{R}=-0.92$ for females) between $L_{\infty}$ and $k$ estimates (Table 3, Fig. 4). Correlation between parameters did not seem to be determined by age-atcapture (Figs 4, S5), which indicated that the number of observations available for each individual did not influence estimation. Females generally grew to larger sizes than males, with the largest difference found in the Celtic Sea. Females also grew faster than males, except in the Celtic Sea.

\subsection{Spatial analysis}

At the population level, growth was found to differ between all ICES divisions for males, whereas no difference could be found between the Bay of Biscay and English Channel for females (Table 4). For both sexes, models with North Sea divisions (South, Central, North) separated were always preferred to models with any combination of these divisions (all combinations were tried, some are shown in Table 4). Variability between areas $\sigma_{b}$ was lower than residual variability for males, whereas a larger part of variability could be described by spatial differences in $L_{\infty}$ for females (Table 5). Again a high, negative correlation between $L_{\infty}$ and $k$ estimates was found for both sexes (Table 5). Females grew to the largest sizes in Western Waters (Bay of Biscay and English Channel combined), and intermediate size in the Northern North Sea; initial size was largest in the English Channel (Fig. 5a). Male growth patterns were similar, except for the largest initial size found in the Bay of Biscay (Fig. 5b). 


\subsection{Temporal analysis}

Time series of estimated cohort-specific growth parameters differed between the Northern and Central North Sea (Fig. 6). Temporal fluctuations of female growth parameters were not significantly correlated (asynchronic) between the Northern and Central North Sea, while males varied in moderate synchrony (Table 4; Fig. 6). Both temperature and density were found to affect at least one growth parameter, with different strengths depending on sex (Table 7). There was sometimes an additional area effect, suggesting differences in growth parameters between areas that was not entirely explained by this factor. However, the interactions between factors and area were never significant, suggesting that there is no difference in response to the environment between the Northern and Central North Sea (Table 7).

\section{Discussion}

Both at the population and individual levels, we found differences in whiting growth between the North Sea, English Channel, and Celtic Sea. In contrast, the analysis of individual growth trajectories did not provide evidence for a difference between the Southern and Central North Sea, whereas the analysis at the population level did. The time-series analysis confirmed differences in growth fluctuations between the Northern and Central North Sea, but did not provide evidence of differential responses to the environment between these areas. Overall, our results suggest that the current assessment and/or management units might deserve revision, by considering defining separate stock units for the Celtic Sea, English Channel, and perhaps even within the North Sea. The latter result is consistent with the results of the genetic study by Charrier et al. (2007), and with different trends in Spawning Stock Biomass reported for southern and northern North Sea whiting, which was interpreted to suggest different sub-populations (Holmes et al., 2014).

The discrepancy between the results for the individual growth trajectories analysis (no difference between Southern and Central North Sea) and the spatial analysis at the population level (Southern, Central and Northern North Sea different) could result from their different spatial or temporal data coverages. Spatial data coverages differed since the Northern North Sea could not be included in the individual analysis due to lack of data, whereas this area seems to display the most contrasting growth curves. However, grouping the Southern and Central North Sea at the population level did not result in better model fits than keeping those areas separated. Thus, the difference in spatial coverage does not explain the inconsistency. Temporal coverage also differed, with the individual analysis spanning 1997 to 2009, and the population-level analysis 2005 to 2012. The results of the temporal analysis showed that growth parameters fluctuated widely in time, thus temporal differences might indeed contribute to the discrepancy. Moreover, individual growth curves displayed a wide diversity of shapes (Figs 3, S4), which might be better captured by the analysis of individual trajectories than of length-at-age at the population level. In addition, a larger sample size could be achieved for the population level analysis, potentially resulting in a higher power.

This study suggests that growth analysis can contribute to stock identification. Given the high between-individual variability in growth, large differences are required to provide statistical significance. For example, given the size of the standard deviation of the random effect for female whiting individuals ( $\sigma_{w}$ in Table 3 ), a difference of least $4 \mathrm{~cm}$ in $L_{\infty}$, or $0.12 \mathrm{yr}^{-1}$ units in $k$, is required to be able to detect a difference with a 0.05 type I error risk. However, differences of this magnitude or larger were actually found between areas. Obviously these results do not provide a definite answer to the question, however, they can 
contribute to inform interdisciplinary stock identification as outlined by Cadrin et al. (2014). Differences in asymptotic size as large as $20 \mathrm{~cm}$, or in growth rate as large as $0.3 \mathrm{yr}^{-1}$, as found between the Celtic Sea and English Channel or even between the Northern and Southern North Sea, are relevant to stock identification, as they might result in quite contrasted productivities and responses to fishing. Mixed effect models proved useful tools to this endeavour, as they provide a parcimonious method to analyse variances at several nested levels.

Consistently with previous findings (e.g., Baudron et al., 2014; Hunter et al., 2016; Trenkel et al., 2015), we found some evidence of negative impacts of warmer temperatures on asymptotic size, and some density-dependence in growth rate. As outlined by Hunter et al. (2016), growth varies in response to many drivers and a study of their respective influence would require a careful, case-specific selection of the variables and time delays. This was not the purpose of this study, which was rather meant to illustrate a methodology to evidence differential stock responses to the environment.

Potential methodological weaknesses of this study include the use of samples collected using length-stratification and the parameterization of the von Bertalanffy growth model. Length-stratified data have been shown to result in potentially biased estimates of mean length-at-age (Bettoli and Miranda, 2001). This is partly corrected for here by the analysis of cohorts rather than years, and by balancing the data across cohorts. The high correlation found between the estimated growth parameters could be seen as an artefact of the von Bertalanffy growth model parameterization (Schnute, 1981). However, a different parameterization was tried and resulted in similarly high correlations (Table S3, to be compared to Table 3). Recent bio-energetic modelling studies suggest that there is indeed a biological, negative correlation between $L_{\infty}$ and $k$, which results from the interactions between growth and maturation processes (e.g., Brunel et al., 2013; Lester et al., 2004; Quince et al., 2008).

\section{Acknowledgements}

We are grateful to the captains and crews of the vessels and scientists working onboard and at the laboratory for assistance with sampling, and Jean-Louis Dufour and Robert Bellail for age readings. We thank Philippe Vernon and Didier Gascuel for fruitful discussions during the development of this study, and three anonymous reviewers for their helpful comments on an earlier version of this manuscript. This study was supported by the Data Collection Framework (DCF; EC Reg. 199/2008, 665/2008; Decisions 2008/949/EC and 2010/93/EU).

\section{References}

Abaunza, P., Gordo, L.S., García Santamaría, M.T., Iversen, S.A., Murta, A.G., Gallo, E., 2008. Life history parameters as a basis for the initial recognition of stock management units in horse mackerel (Trachurus trachurus). Fish. Res. 89, 167-180.

Baudron, A.R., Needle, C.L., Rijnsdorp, A.D., Marshall, C.T., 2014. Warming temperatures and smaller body sizes: synchronous changes in growth of North Sea fishes. Glob. Chang. Biol. 20, 1023-1031.

Bettoli, P.W., Miranda, L.E., 2001. Cautionary note about estimating mean length at age with subsampled data. N. Am. J. Fish. Manage. 21, 425-428. 
Brunel, T., Ernande, B., Mollet, F.M., Rijnsdorp, A.D., 2013. Estimating age at maturation and energy-based life-history traits from individual growth trajectories with nonlinear mixed-effect models. Oecologia 172, 631-643.

Cadrin, S.X., Kerr, L.A., Mariani, S., 2014. Interdisciplinary evaluation of spatial population structure for definition of fishery management units. In: Cadrin, S.X., Kerr, L.A., Mariani, S.s (Eds.), Stock identification methods: Applications in fisheries science. 2nd edition. Elsevier, London, pp. 535-552.

Carpentier, A., Martin, C.S., Vaz, S., 2009. Channel habitat atlas for marine resource management, Final Report (CHARM). http://archimer.ifremer.fr/doc/00000/7377/ Ifremer, Boulogne-sur-mer, 626 p.

Charrier, G., Coombs, S.H., McQuinn, I.H., Laroche, J., 2007. Genetic structure of whiting Merlangius merlangus in the northeast Atlantic and adjacent waters. Mar. Ecol. Prog. Ser. 330, 201-211.

Claireaux, M., 2013. Changements temporels de traits d'histoire de vie chez la sole de Manche Est. Mémoire de master 1. Université de Bretagne Occidentale, Brest, 27 p.

Cohen, D.M., Inada, T., Iwamoto, T., Scialabba, N., 1990. Gadiform fishes of the world (Order Gadiformes): an annotated and illustrated catalogue of cods, hakes, grenadiers, and other gadiform fishes known to date. FAO Fish. Synop. Food and Agriculture Organization of the United Nations, Rome.

Easey, M., Henderson, G., Shanks, A.M., 2005. Report of the Whiting (Merlangius merlangus) Otolith Exchange Scheme 2004 and Workshop 2005, Cefas Lowestoft, England, 17-20 October 2005 http://www.ices.dk/community/Documents/PGCCDBS/whg.agewk2005.pdf. 80 p.

Francis, R.I.C.C., 1990. Back-calculation of fish length: a critical review. J. Fish Biol. 36, 883-902.

Gibb, F.M., Wright, P.J., Gibb, I.M., O'Sullivan, M., 2004. Haddock and whiting spawning areas in the North Sea and Scottish west coast. Fisheries Research Services, Internal Report 11/04. http://www.gov.scot/Uploads/Documents/IR1104.pdf. 11 p.

Hehir, I., 2003. Age, growth and reproductive biology of whiting Merlangius merlangus in the Celtic Sea. Master of Science in Fisheries and Marine Biology. http://hdl.handle.net/10759/313355 Galway-Mayo Institute of Technology, Galway, Ireland.

Heino, M., 2014. Quantitative traits. In: Cadrin, S.X., Kerr, L.A., Mariani, S.s (Eds.), Stock identification methods: Applications in fisheries science. 2nd edition. Elsevier, London, pp. 59-76.

Hislop, J.R.G., 1984. A comparison of the reproductive tactics and strategies of cod, haddock, whiting and Norway pout in the North sea. In: Potts, G.W., Wootton, R.J.s 
(Eds.), Fish reproduction: Strategies and tactics. Academic Press, London, pp. 311329.

Holmes, S.J., Millar, C.P., Fryer, R.J., Wright, P.J., 2014. Gadoid dynamics: differing perceptions when contrasting stock vs. population trends and its implications to management. ICES J. Mar. Sci. 71, 1433-1442.

Hunter, A., Speirs, D.C., Heath, M.R., 2016. Investigating trends in the growth of five demersal fish species from the Firth of Clyde and the wider western shelf of Scotland. Fish. Res. 177, 71-81.

Huret, M., Sourisseau, M., Petitgas, P., Struski, C., Léger, F., Lazure, P., 2013. A multidecadal hindcast of a physical-biogeochemical model and derived oceanographic indices in the Bay of Biscay. J. Marine Syst. 109-110, S77-S94.

ICES, 1996. Manual for the International Bottom Trawl Surveys. Addendum to ICES C.M. 1996 / H: 1. ICES, 58 p.

Keyl, F., Kempf, A.J., Sell, A.F., 2015. Sexual size dimorphism in three North Sea gadoids. J. Fish Biol. 86, 261-275.

Lauerburg, R.A.M., Keyl, F., Kotterba, P., Floeter, J., Temming, A., 2015. Sex-specific food intake in whiting Merlangius merlangus. J. Fish Biol. 86, 1729-1753.

Leblond, E., Daurès, F., Berthou, P., Dintheer, C., 2008. The Fisheries Information System of Ifremer: a multidisciplinary monitoring network and an integrated approach for the assessment of French fisheries, including small-scale fisheries. ICES CM 2008/ K: 11 .

Lester, N.P., Shuter, B.J., Abrams, P.A., 2004. Interpreting the von Bertalanffy model of somatic growth in fishes: the cost of reproduction. Proc. R. Soc. B 271, 1625-1631.

Lowe, W.H., Allendorf, F.W., 2010. What can genetics tell us about population connectivity? Mol. Ecol. 19, 3038-3051.

Macdonald, P., Angus, C.H., Marshall, C.T., 2013. Spatial variation in life history characteristics of common megrim (Lepidorhombus whiffiagonis) on the Northern Shelf. J. Sea Res. 75, 62-68.

McBride, R.S., 2014. The continuing role of life history parameters to identify stock structure. In: Cadrin, S.X., Kerr, L.A., Mariani, S. (Eds.), Stock identification methods: Applications in fisheries science. 2nd edition. Elsevier, London, pp. 77107.

Morrongiello, J.R., Thresher, R.E., 2015. A statistical framework to explore ontogenetic growth variation among individuals and populations: a marine fish example. Ecol. Monogr. 85, 93-115. 
Nielsen, E.E., Hemmer-Hansen, J., Larsen, P.F., Bekkevold, D., 2009. Population genomics of marine fishes: identifying adaptive variation in space and time. Mol. Ecol. 18, 3128-3150.

Panfili, J., de Pontual, H., Troadec, H., Wright, P.J. (Eds.), 2002. Manual of fish sclerochronology. Ifremer - $\quad$ IRD, Brest, France. http://archimer.ifremer.fr/doc/00017/12801/9742.pdf.

Pinnegar, J.K., Trenkel, V.M., Tidd, A.N., Dawson, W.A., Du Buit, M.H., 2003. Does diet in Celtic Sea fishes reflect prey availability? J. Fish Biol. 63 (Supplement A), 197-212.

Quince, C., Abrams, P.A., Shuter, B.J., Lester, N.P., 2008. Biphasic growth in fish I: theoretical foundations. J. Theor. Biol. 254, 197-206.

Reiss, H., Hoarau, G., Dickey-Collas, M., Wolff, W.J., 2009. Genetic population structure of marine fish: mismatch between biological and fisheries management units. Fish Fish. 10, 361-395.

Riley, J.D., Symonds, D.J., Woolner, L.E., 1986. Determination of the distribution of the planktonic and small demersal stages of fish in the coastal waters of England, Wales and adjacent areas between 1970 and 1984. Fisheries Research Technical Report, MAFF, Lowestoft. https:/www.cefas.co.uk/publications/techrep/tech84.pdf, 23 p.

Ross, S.D., Hüssy, K., 2013. A reliable method for ageing of whiting (Merlangius merlangus) for use in stock assessment and management. J. Appl. Ichthyol. 29, 825832.

Schnute, J., 1981. A versatile growth model with statistically stable parameters. Can. J. Fish. Aquat. Sci. 38, 1128-1140.

Sequeira, V., Neves, A., Barros Paiva, R., Pereira de Lima, J., Rita Vieira, A., Serrano Gordo, L., 2012. Life history parameters as possible discriminators of bluemouth Helicolenus dactylopterus (Delaroche, 1809) populations in Portuguese waters. Fish. Res. 125-126, 69-76.

Shelton, A.O., Satterthwaite, W.H., Beakes, M.P., Munch, S.B., Sogard, S.M., Mangel, M., 2013. Separating intrinsic and environmental contributions to growth and their population consequences. Am. Nat. 181, 799-814.

Thorson, J.T., Minto, C., 2015. Mixed effects: a unifying framework for statistical modelling in fisheries biology. ICES J. Mar. Sci. 72, 1245-1256.

Trenkel, V.M., Lorance, P., Fässler, S.M.M., Høines, A.S., 2015. Effects of density dependence, zooplankton and temperature on blue whiting Micromesistius poutassou growth. J. Fish Biol. 87, 1019-1030.

Vigliola, L., Harmelin-Vivien, M., Meekan, M.G., 2000. Comparison of techniques of back-calculation of growth and settlement marks from the otoliths of three species of Diplodus from the Mediterranean Sea. Can. J. Fish. Aquat. Sci. 57, 1291-1299. 
Vincenzi, S., Mangel, M., Crivelli, A.J., Munch, S.B., Skaug, H.J., 2014. Determining individual variation in growth and its implication for life-history and population processes using the empirical Bayes method. PLOS Comp. Biol. 10, e1003828. 


\section{Figure}

Figure 1. Map of whiting stock structures in the North East Atlantic: management units (dotted lines, Reiss et al., 2009), assessement units (continuous lines, http://www.ices.dk/community/advisory-process/Pages/Latest-advice.aspx), and stock structure suggested by recent genetic studies (dashed lines, Charrier et al., 2007). ICES divisions are shown in black as a background: IVa Northern North Sea, IVb Central North Sea, IVc Southern North Sea, VIId Eastern English Channel, VIIf,g,h,j Celtic Sea, and VIIIab Bay of Biscay.

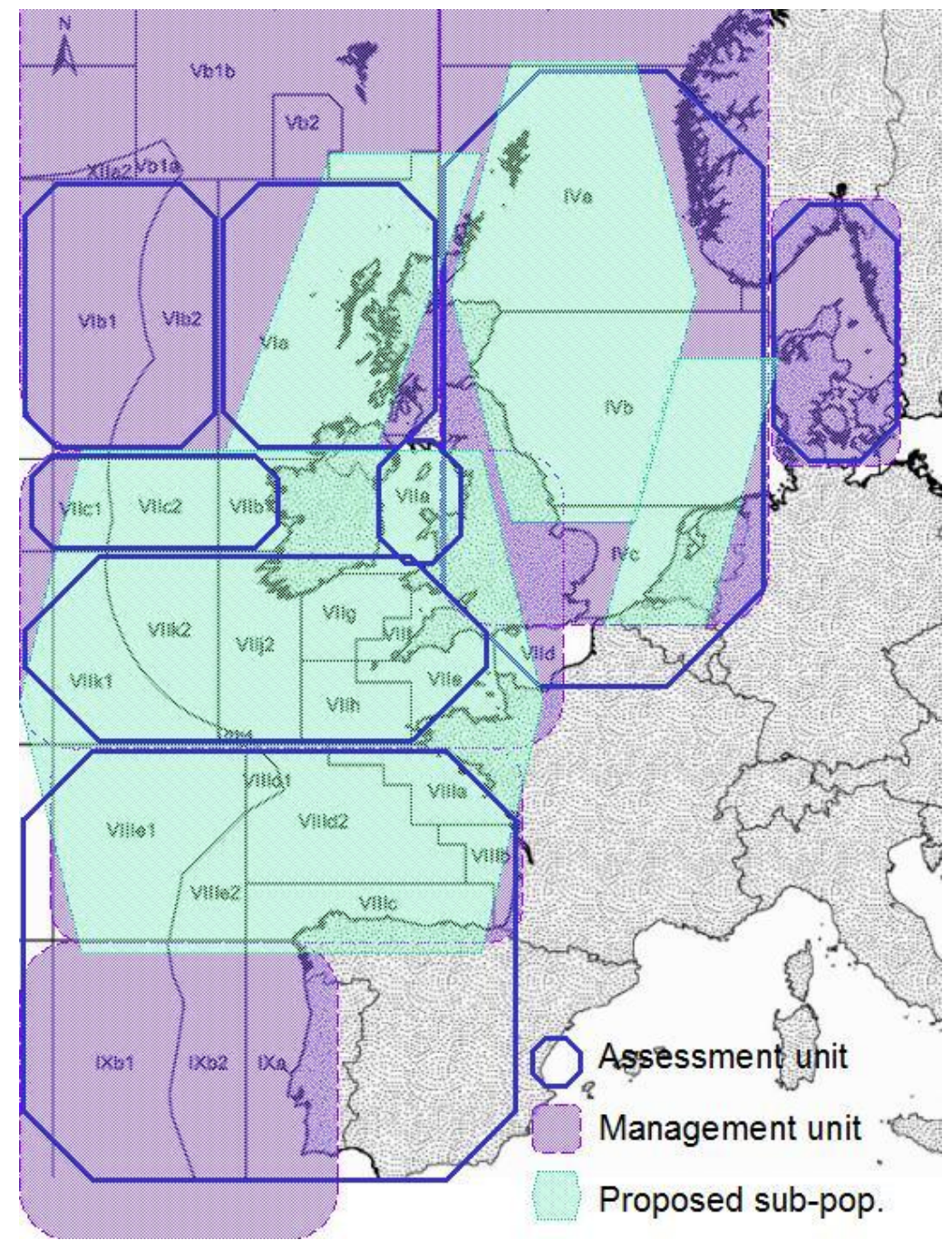


Figure 2. (a) Total fish length - otolith radius non-linear regression for female whiting, all areas $(n=390)$. (b) Model-based estimated total length versus length-at-capture for female whiting. Slope $=0.96(\mathrm{Sd} 0.004), \mathrm{R}^{2}=0.99, \mathrm{n}=390$.

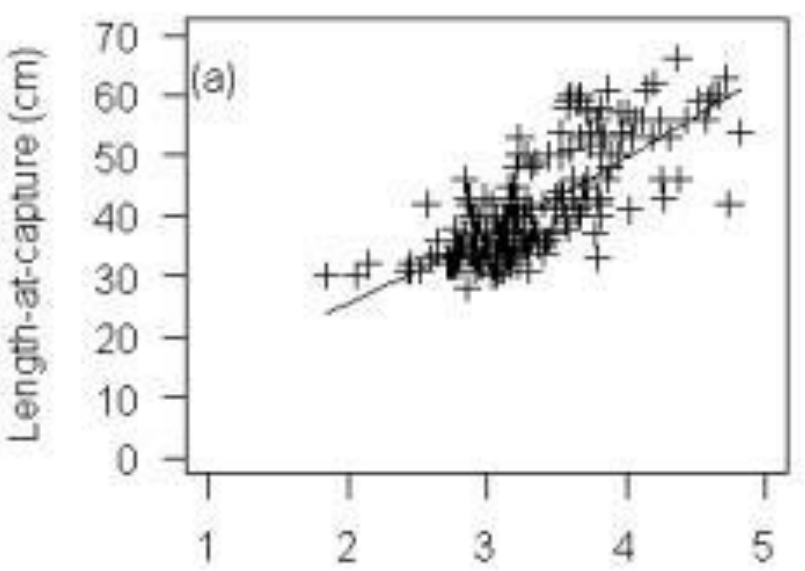

Otolith radius (mm)

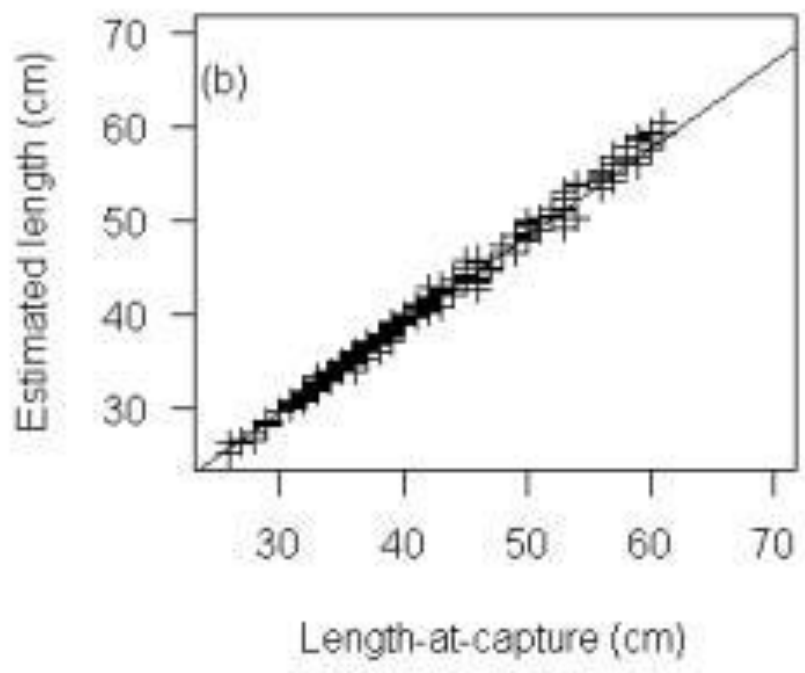

Figure 3. Reconstructed female individual growth trajectories per ICES division. Each cohort (year of birth) is plotted with a different colour.

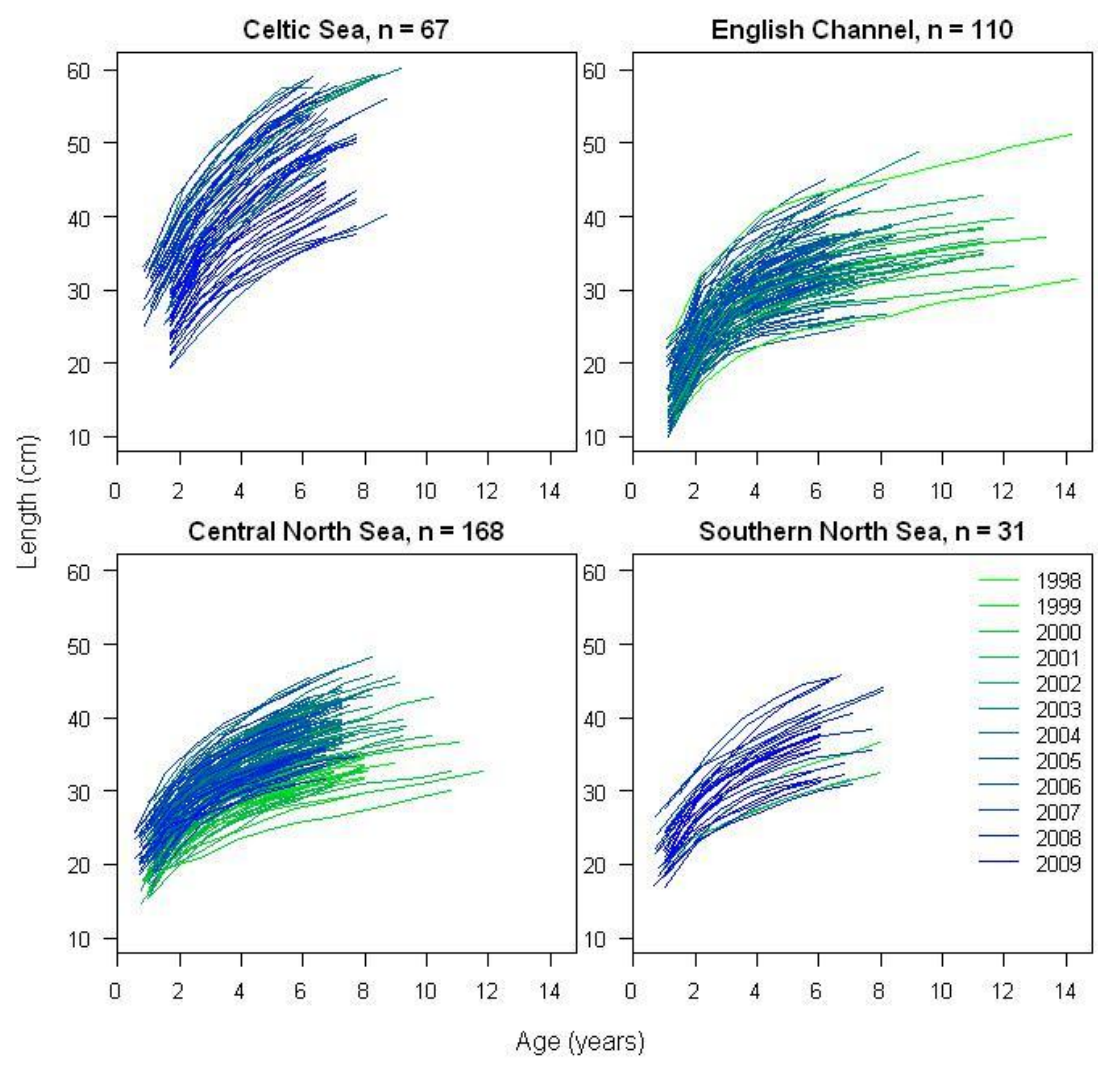


Figure 4. Estimates of individual growth parameters from the mixed effects model of individual growth trajectories of female whiting.

\section{Female whiting}
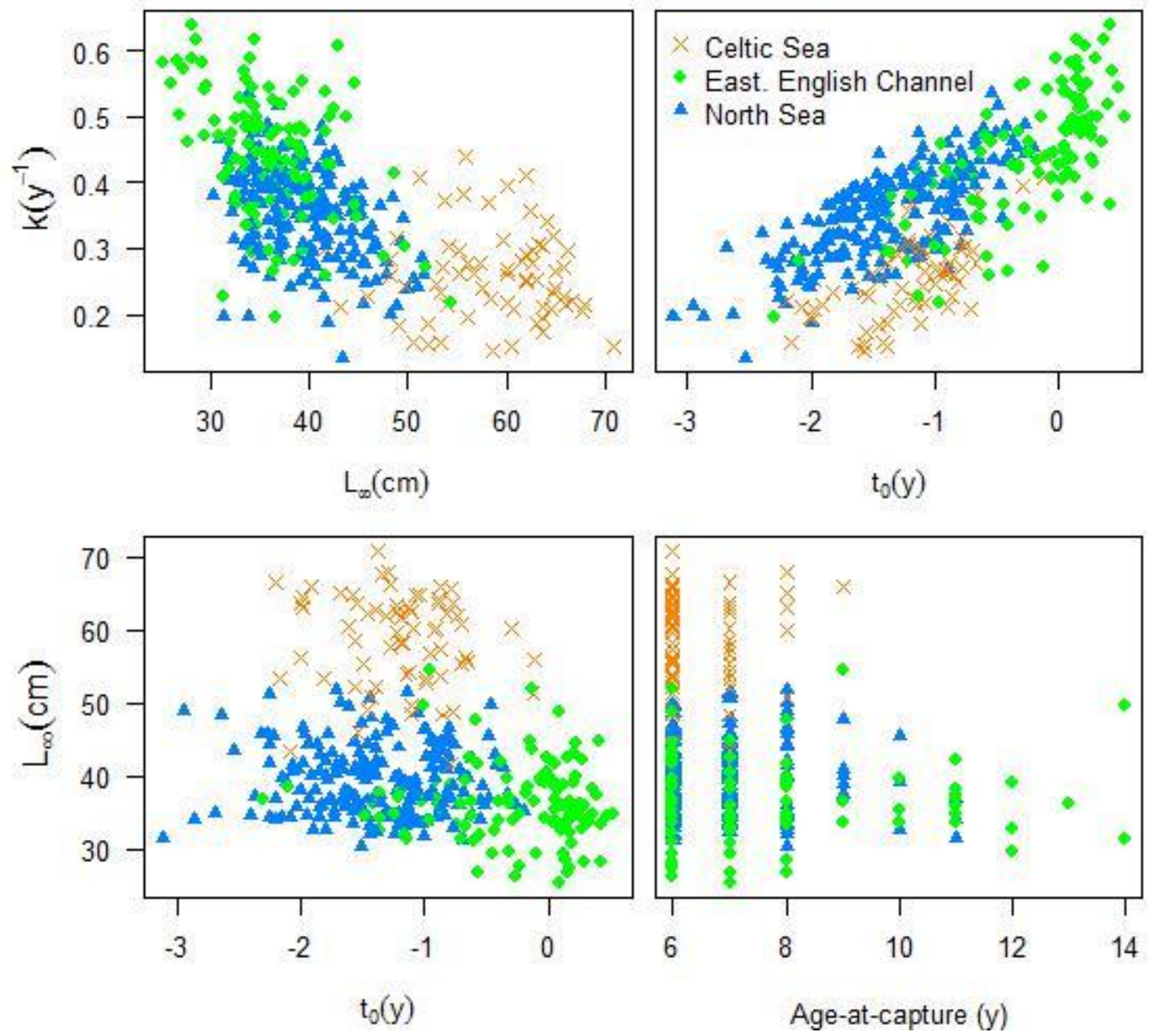
Figure 5. Population-level growth curves per area for (a) female and (b) male whiting. Areas are as identified as significantly different from each other by the model selection procedure (see Table 4). Western Waters: Celtic Sea and Bay of Biscay grouped.

(a) Female

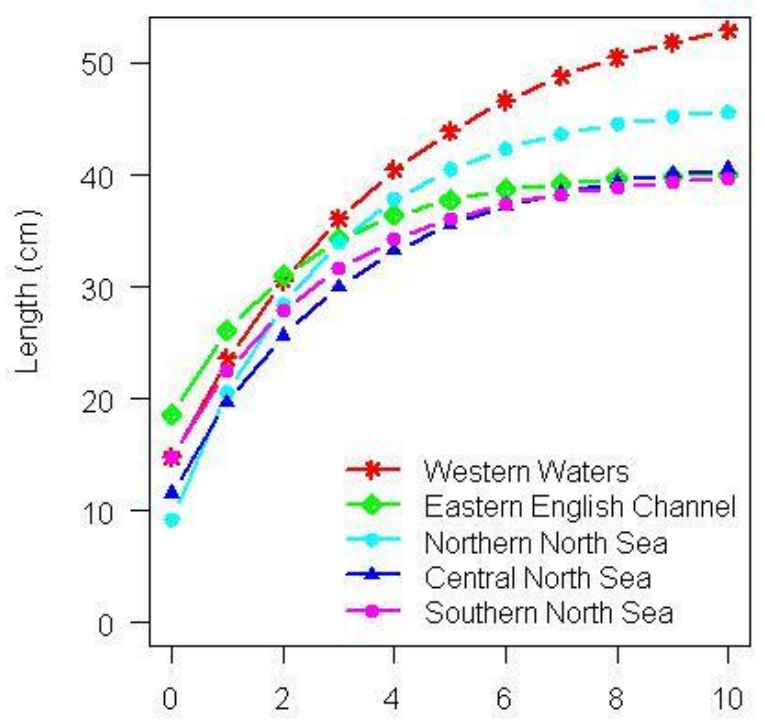

(b) Male

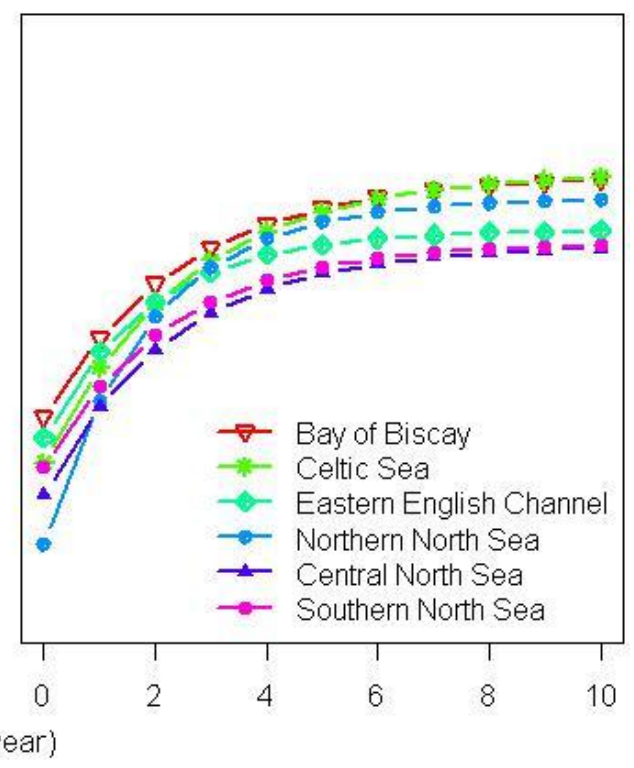

Figure 6. Time series of growth parameter estimates per division for female and male whiting.

Female
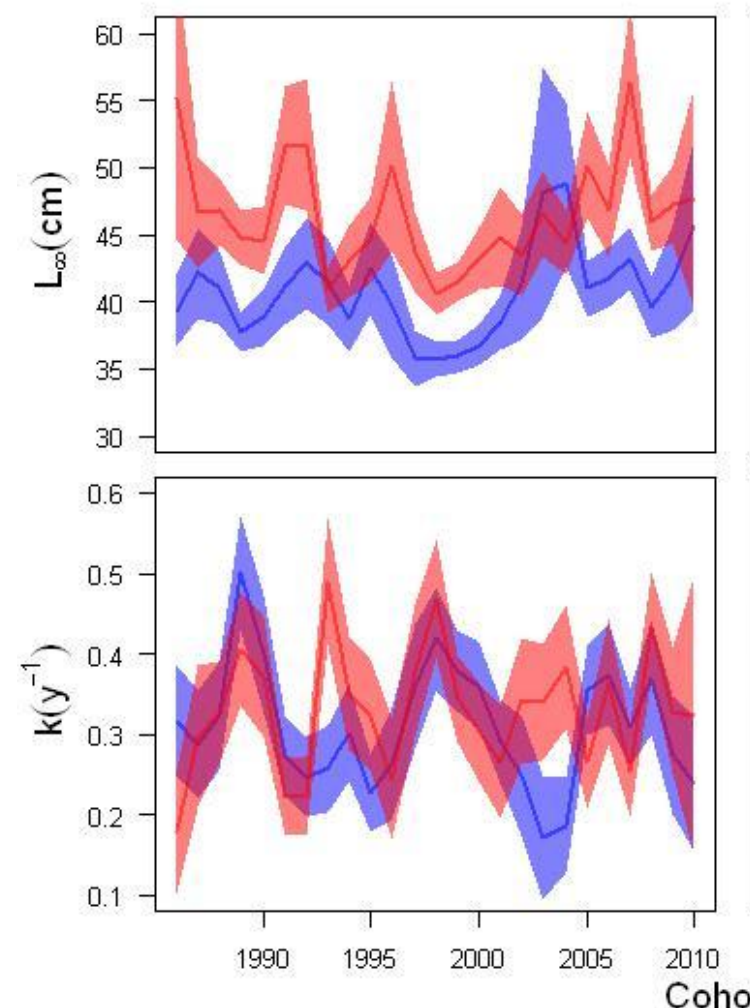

Male
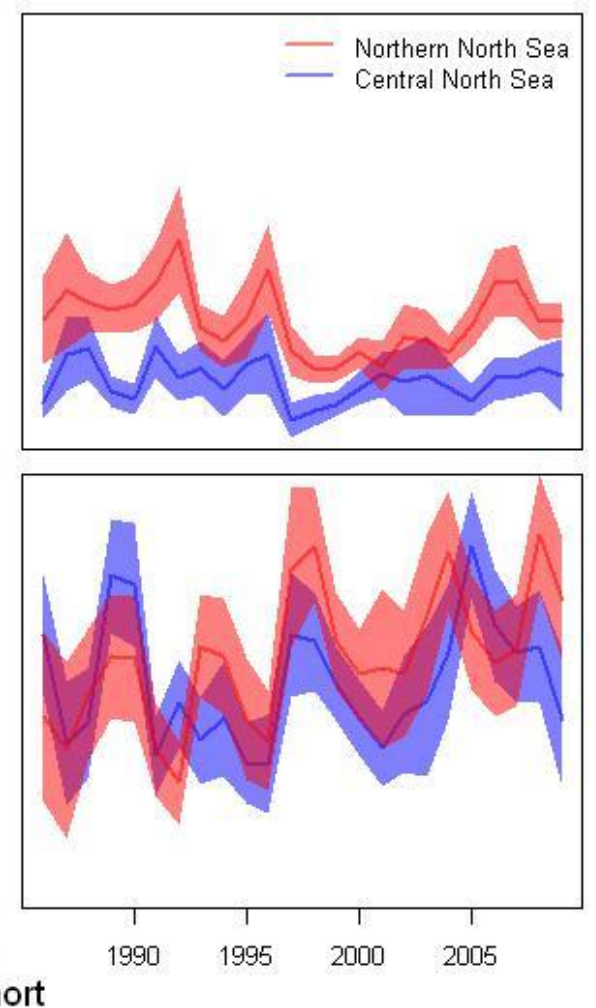
Table 1. Results of non-linear regression between total body length $L_{\mathrm{t}}$ and otolith radius $R_{\mathrm{t}}$ for female and male whiting $L_{t}=a+b R_{t}^{c}$. Sd Standard deviation. n number of individuals.

\begin{tabular}{lcccccccc}
\multicolumn{7}{c}{ Parameter estimates } \\
\hline Females & $\mathrm{a}$ & $\mathrm{Sd}(\mathrm{a})$ & $\mathrm{b}$ & $\mathrm{Sd}(\mathrm{b})$ & $\mathrm{c}$ & $\mathrm{Sd}(\mathrm{c})$ & $\mathrm{R}^{2}$ & $\mathrm{n}$ \\
Males & 0.31 & 0.11 & 6.12 & 6.49 & 1.35 & 0.53 & 0.75 & 390 \\
\hline
\end{tabular}

Table 2. Model selection for individual growth trajectories. AIC Akaike Information Criterion for models by sex: (i) random effect for individuals and (ii-iii) random effect for individuals nested in random effect for areas (ii: 3 areas = Central and Sourthern North Sea, Eastern English Channel, Celtic Sea, iii: 4 areas = Central North Sea, Sourthern North Sea, Eastern English Channel, Celtic Sea) for the three growth parameters of the von Bertalanffy model. Selected models are in bold.

\begin{tabular}{lccl}
\hline \multicolumn{1}{c}{ Model } & Degrees of freedom & Females & Males \\
\hline (i) Indiv. & 10 & 8620.8 & 4787.5 \\
(ii) Area (3 levels)/Indiv & $\mathbf{1 6}$ & $\mathbf{8 0 9 3 . 8}$ & $\mathbf{4 5 5 3 . 8}$ \\
(iii) Area (4 levels)/Indiv & 16 & 8100.8 & 4559.5 \\
\hline
\end{tabular}

Table 3. Fixed and random effects estimates for whiting individual growth parameters. Females: 376 individuals, 2610 observations; males: 256 individuals, 1760 observations.

\begin{tabular}{lcccccc}
\hline & \multicolumn{3}{c}{ Females } & \multicolumn{3}{c}{ Males } \\
\hline Parameter & $L_{\infty}$ & $t_{0}$ & $k$ & $L_{\infty}$ & $t_{0}$ & $k$ \\
\hline Fixed effect & 44.77 & -0.95 & 0.35 & 36.11 & -1.06 & 0.35 \\
$\sigma_{b}$ & 9.83 & 0.49 & 0.07 & 3.73 & 0.60 & 0.06 \\
Correlation with $L_{\infty}$ & & -0.490 & -0.924 & & 0.228 & -0.722 \\
Correlation with $t_{0}$ & & & 0.786 & & & 0.515 \\
$\sigma_{w}$ & 5.40 & 0.60 & 0.09 & 3.39 & 0.73 & 0.10 \\
Correlation with $L_{\infty}$ & & -0.125 & -0.372 & & -0.500 & -0.627 \\
Correlation with $t_{0}$ & & & 0.737 & & & 0.797 \\
Residual & & 0.52 & & & 0.41 & \\
\hline
\end{tabular}


Table 4. Model selection for grouped areas-level growth models: Akaike Information Criterion for models by sex: area random effect on the three growth parameters (i) North Sea, Eastern English Channel, Celtic Sea, Bay of Biscay; (ii) North Sea and Eastern English Channel, Celtic Sea, Bay of Biscay; (iii) Northern and Central North Sea, Southern North Sea and Eastern English Channel, Celtic Sea, Bay of Biscay, (iv) Northern North Sea, Central North Sea, Southern North Sea, Eastern English Channel, Celtic Sea, Bay of Biscay, (v) Northern North Sea, Central North Sea, Southern North Sea, Celtic Sea, Eastern English Channel and Bay of Biscay, and (vi) Northern North Sea, Central and Southern North Sea, Celtic Sea, Eastern English Channel and Bay of Biscay. Selected models are in bold. NC model did not converge.

\begin{tabular}{lcccc}
\hline \multicolumn{2}{c}{ Model, no areas } & Degrees of freedom & Females & Males \\
\hline (i) & 4 & 10 & 63503 & 51358 \\
(ii) & 3 & 10 & 64303 & NC \\
(iii) & 4 & 10 & 63592 & 51840 \\
(iv) & 6 & 10 & 62414 & $\mathbf{4 9 6 7 6}$ \\
(v) & 5 & 10 & $\mathbf{6 2 4 0 9}$ & 50280 \\
(vi) & 4 & 10 & 62659 & 50414 \\
\hline
\end{tabular}

Table 5. Random effects estimates for whiting growth parameters, spatial analysis at population level. Females: 10735 observations, 5 areas (Northern North Sea, Central North Sea, Southern North Sea, Celtic Sea, Eastern English Channel and Bay of Biscay); males: 9105 observations, 6 areas (Northern North Sea, Central North Sea, Southern North Sea, Eastern English Channel, Celtic Sea, Bay of Biscay).

\begin{tabular}{lccccrr}
\hline Level / Parameter & \multicolumn{3}{c}{ Females } & \multicolumn{3}{c}{ Males } \\
\hline & Estimate & \multicolumn{2}{c}{ Correlation } & Estimate & Correlation \\
\hline Area & $\sigma_{b}$ & & & $\sigma_{b}$ & & \\
$L_{\infty}$ & 7.22 & $L_{\infty}$ & $t_{0}$ & 2.81 & $L_{\infty}$ & $t_{0}$ \\
$t_{0}$ & 0.29 & -0.024 & & 0.37 & -0.151 & \\
$k$ & 0.07 & -0.867 & 0.098 & 0.07 & -0.401 & 0.635 \\
Residuals & 4.41 & & & 3.68 & & \\
\hline
\end{tabular}

Table 6. Temporal correlation coefficients between Northern North Sea and Central North Sea estimates of growth parameters. Significant correlations at $\alpha=0.05$ are in bold.

\begin{tabular}{lcc} 
& Females & Males \\
\hline$L_{\infty}$ & 0.31 & $\mathbf{0 . 5 4}$ \\
$k$ & 0.29 & $\mathbf{0 . 4 5}$ \\
\hline
\end{tabular}


Table 7. Selection of explanatory variables for temporal (cohort) variation in parameters of von Bertalanffy growth model by sex: P-values for comparison of nested models of increasing complexity (type I analysis of variance). For each factor (temperature and whiting density), the first line (a) is the P-value of a linear model with the factor (temperature or density) as single explanatory variable; the next two lines are P-values for comparison with the model on the line above, with (b) area effect added to the factor, and (c) interaction between the factor and area.

\begin{tabular}{lccccccc}
\hline Explanatory variables & \multicolumn{3}{c}{ Female } & \multicolumn{3}{c}{ Male } \\
\hline & $L_{\infty}$ & $k$ & $t_{0}$ & $L_{\infty}$ & $k$ & $t_{0}$ \\
(a) Temperature & $\mathbf{0 . 0 1 8}$ & 0.29 & $\mathbf{0 . 0 0 5}$ & $\mathbf{1} \mathrm{e}^{-5}$ & 0.88 & 0.24 \\
(b) $\quad+$ area & $4 \mathrm{e}^{-6}$ & 0.90 & 0.29 & $2 \mathrm{e}^{-5}$ & 0.015 & 0.003 \\
(c) $\quad+$ temp $\times$ area & 0.71 & 0.68 & 0.73 & 0.43 & 0.14 & 0.15 \\
\hline (a) Density & 0.08 & 0.92 & $\mathbf{0 . 0 3}$ & 0.88 & $\mathbf{7} \mathrm{e}^{-7}$ & $\mathbf{2} \mathrm{e}^{-6}$ \\
(b) + area & $2 \mathrm{e}^{-5}$ & 0.18 & 0.005 & $6 \mathrm{e}^{-10}$ & 0.39 & 0.009 \\
(c) $\quad+$ density $\times$ area & 0.90 & 0.30 & 0.86 & 0.53 & 0.57 & 0.77 \\
\hline
\end{tabular}


Utility of mixed effects models to inform the stock structure of whiting in the Northeast Atlantic Ocean

Alexander Barrios, Bruno Ernande, Kelig Mahé, Verena Trenkel, Marie-Joëlle Rochet

Supplementary materials

\section{Data used for analyses}

Table S1. Number of individual growth trajectories analysed per sex, year of birth and ICES division. CS Celtic Sea (VIIf-k), EC Eastern English Channel (VIId), NB Central North Sea (IVb), NC Southern North Sea (IVc).

\begin{tabular}{rrrrrrrrr}
\hline & \multicolumn{3}{c}{ Females } & \multicolumn{5}{c}{ Males } \\
\hline Year & CS & \multicolumn{1}{c}{ EC } & \multicolumn{1}{c}{ NB } & NC & CS & EC & NB & NC \\
\hline 1997 & 0 & 0 & 0 & 0 & 0 & 0 & 3 & 0 \\
1998 & 0 & 2 & 0 & 0 & 0 & 0 & 2 & 1 \\
1999 & 0 & 1 & 11 & 1 & 0 & 0 & 4 & 1 \\
2000 & 0 & 3 & 11 & 1 & 0 & 0 & 31 & 5 \\
2001 & 1 & 8 & 26 & 1 & 0 & 1 & 23 & 8 \\
2002 & 0 & 3 & 10 & 0 & 0 & 1 & 8 & 1 \\
2003 & 6 & 3 & 7 & 0 & 0 & 0 & 2 & 0 \\
2004 & 2 & 15 & 39 & 0 & 1 & 1 & 3 & 0 \\
2005 & 4 & 20 & 36 & 0 & 1 & 4 & 13 & 1 \\
2006 & 6 & 43 & 8 & 0 & 2 & 25 & 18 & 0 \\
2007 & 18 & 10 & 10 & 6 & 4 & 25 & 13 & 3 \\
2008 & 21 & 2 & 10 & 6 & 12 & 1 & 16 & 1 \\
2009 & 9 & 0 & 0 & 16 & 8 & 0 & 13 & 0 \\
\hline
\end{tabular}


Table S2. Number of individuals used for length-at-age analysis per ICES division and sex, and time periods covered. Gray cells: data used for spatial analysis. Hatched cells: data used for temporal analysis. BB Bay of Biscay (VIIIab), CS Celtic Sea (VIIf-k), EC Eastern English Channel (VIId), NA Northern North Sea (IVa), NB Central North Sea (IVb), NC Southern North Sea (IVc).

\begin{tabular}{|c|c|c|c|c|c|c|c|c|c|c|c|c|}
\hline \multirow[b]{2}{*}{ Cohort } & \multicolumn{6}{|c|}{ Females } & \multicolumn{6}{|c|}{ Males } \\
\hline & $B B$ & CS & $\mathrm{EC}$ & $\mathrm{NA}$ & NB & $\mathrm{NC}$ & $\mathrm{BB}$ & CS & $\mathrm{EC}$ & NA & NB & $\mathrm{NC}$ \\
\hline 1986 & 0 & 0 & 0 & 301 & 583 & 126 & 0 & 0 & 0 & 253 & 544 & 108 \\
\hline 1987 & 0 & 0 & 0 & 295 & 730 & 130 & 0 & 0 & 0 & 2.2 .3 & 596 & 113 \\
\hline 1988 & 0 & 0 & 0 & 679 & 862 & 163 & 0 & 0 & 0 & 498 & 735 & 125 \\
\hline 1989 & 0 & 0 & 0 & 74. & 1106 & 282 & 0 & 0 & 0 & 591 & 878 & 225 \\
\hline 1990 & 0 & 0 & 0 & - & 1473 & 484 & 0 & 0 & 0 & 637 & 1285 & 380 \\
\hline 1991 & 0 & 3 & 0 & 1053 & 1374 & 348 & 0 & 4 & 0 & 922 & 1305 & 292 \\
\hline 1992 & 0 & 4 & 0 & 861 & 1203 & 413 & 0 & 6 & 0 & 791 & 1119 & 343 \\
\hline 1993 & 0 & 11 & 0 & 697 & 1246 & 402 & 0 & 12 & 0 & 593 & 1176 & 318 \\
\hline 1994 & 0 & 5 & 0 & 754 & 1118 & 333 & 0 & 8 & 0 & 672 & 1030 & 283 \\
\hline 1995 & 0 & 22 & 0 & 522 & 1046 & 325 & 0 & 26 & 0 & 518 & 1044 & 261 \\
\hline 1996 & 0 & 12 & 0 & 466 & 762 & 230 & 0 & 19 & 0 & 510 & 838 & 223 \\
\hline 1997 & 0 & 7 & 0 & 394 & 806 & 239 & 0 & 15 & 0 & 303 & 687 & 174 \\
\hline 1998 & 0 & 14 & 2 & 582 & 1173 & 289 & 0 & 10 & 0 & 514 & 1011 & 235 \\
\hline 1999 & 0 & 41 & 0 & 848 & 1292 & 302 & 0 & 51 & 0 & 79 & 1257 & 198 \\
\hline 2000 & 0 & 35 & 0 & 542 & 992 & 253 & 0 & 28 & 0 & 542 & 959 & 209 \\
\hline 2001 & 0 & 64 & 0 & 351 & 915 & 186 & 0 & 52 & 1 & 350 & 1017 & 165 \\
\hline 2002 & 0 & 101 & 3 & 259 & 385 & 27 & 0 & 98 & 2 & 267 & 172 & 38 \\
\hline 2003 & 1 & 63 & 6 & 321 & 388 & 45 & 0 & 75 & 4 & 264 & 406 & 47 \\
\hline 2004 & 0 & 146 & 41 & 433. & 453. & 48 & 3 & 118 & 18 & 380 & 396 & 28 \\
\hline 2005 & 6 & 111 & 71 & 515 & 611 & 96 & 10 & 98 & 41 & 442 & 579 & 52 \\
\hline 2006 & 15 & 98 & 168 & 336 & 547 & 149 & 22 & 90 & 106 & 302 & 491 & 124 \\
\hline 2007 & 43 & 87 & 282 & 378 & 929 & 256 & 30 & 90 & 174 & 355 & 858 & 207 \\
\hline 2008 & 67 & 106 & 202 & 364 & 490 & 140 & 62 & 92 & 132 & 349 & 464 & 109 \\
\hline 2009 & 65 & 153 & 256 & 326 & 582 & 209 & 85 & 110 & 161 & 363 & 522 & 170 \\
\hline 2010 & 56 & 118 & 237 & 246 & 518 & 180 & 58 & 84 & 179 & 199 & 450 & 177 \\
\hline 2011 & 4 & 142 & 134 & 202 & 289 & 161 & 5 & 100 & 90 & 176 & 216 & 100 \\
\hline 2012 & 44 & 113 & 83 & 222 & 235 & 93 & 26 & 61 & 56 & 189 & 186 & 63 \\
\hline
\end{tabular}


2 Length-at-age data
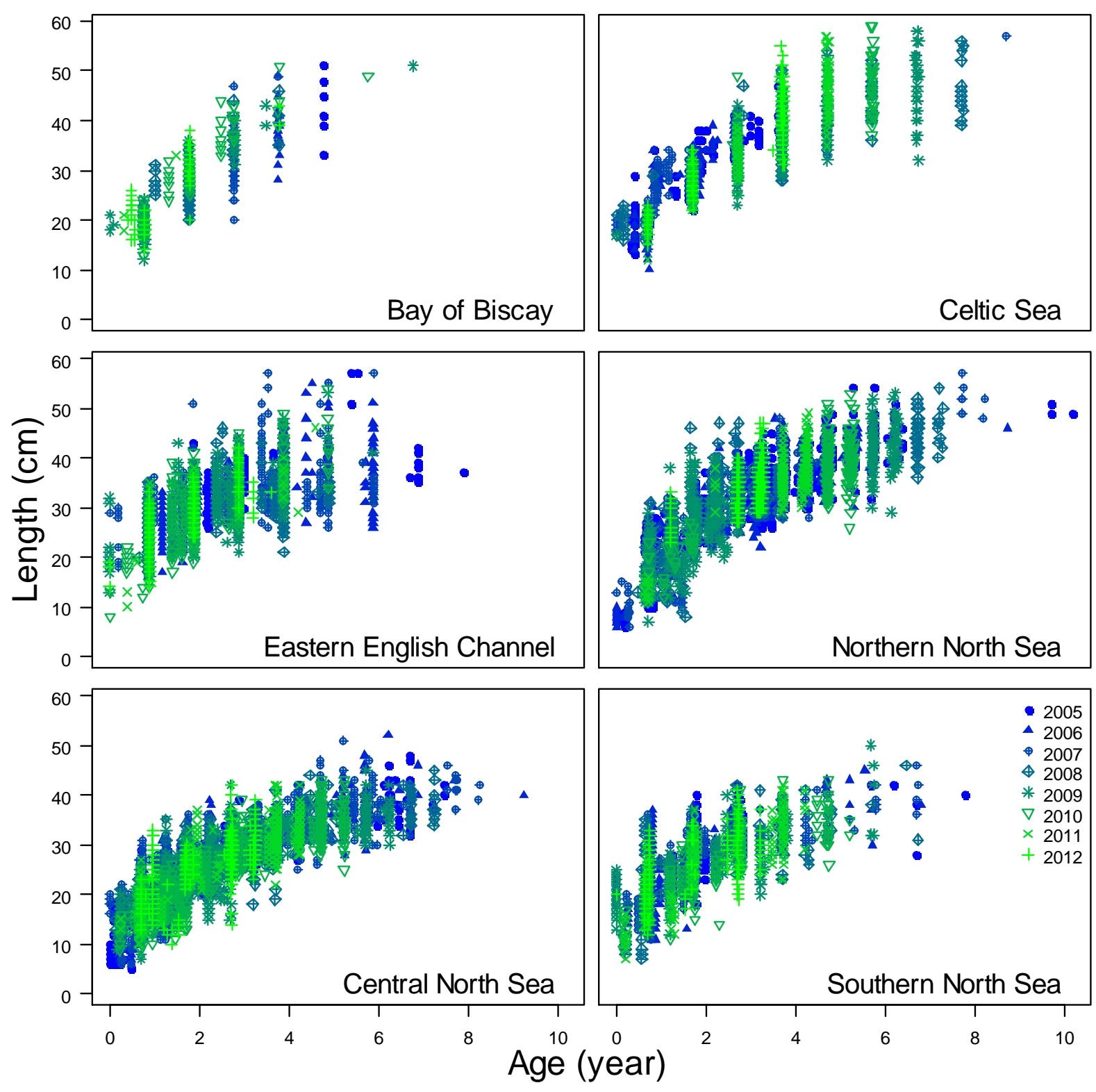

Figure S1. Length-at-age data per cohort and ICES division used in the spatial analysis of female whiting growth. 

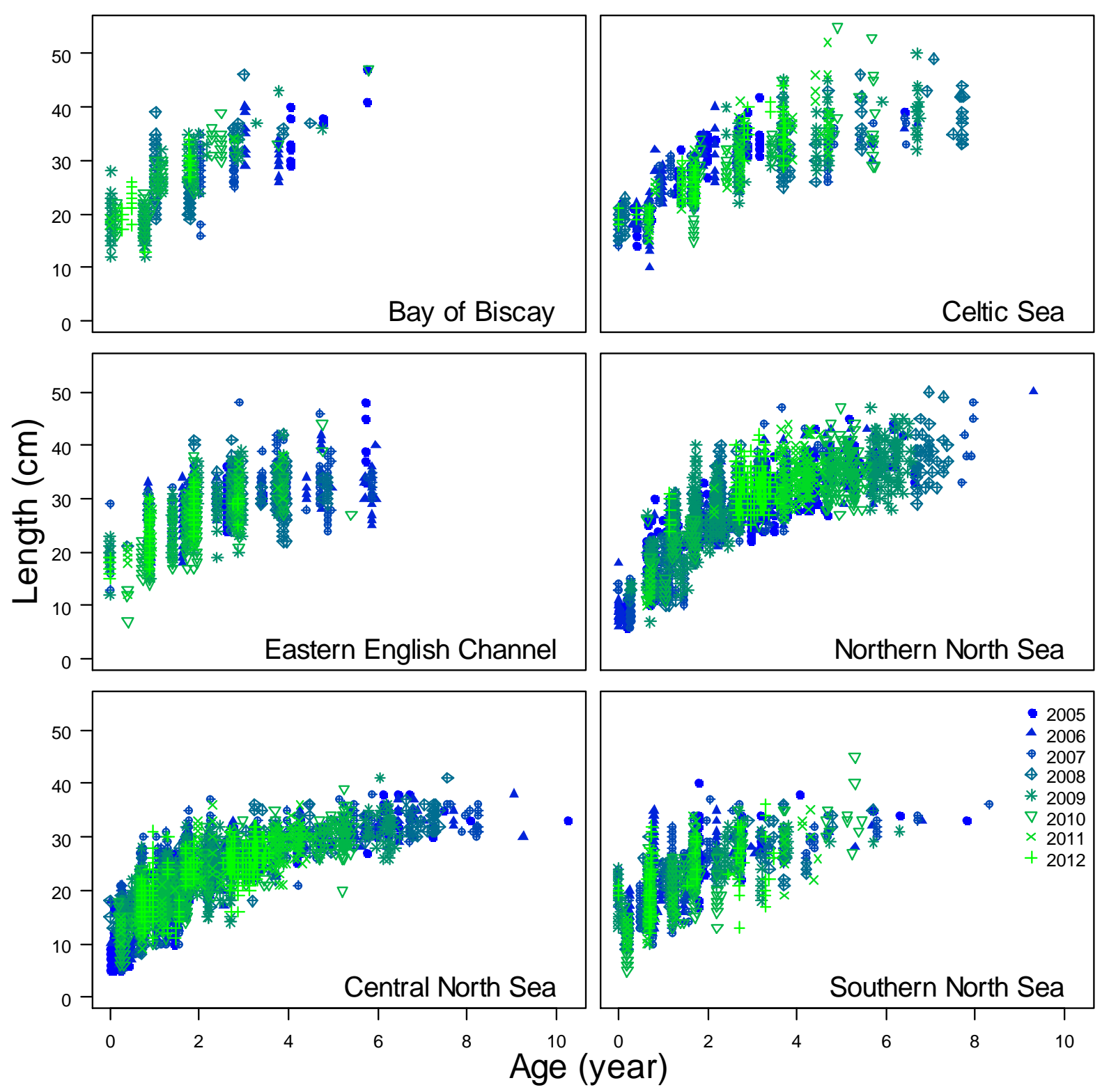

Figure S2. Length-at-age data per cohort and ICES division used in the spatial analysis of male whiting growth. 
3 Reconstructing individual growth trajectories of male whiting

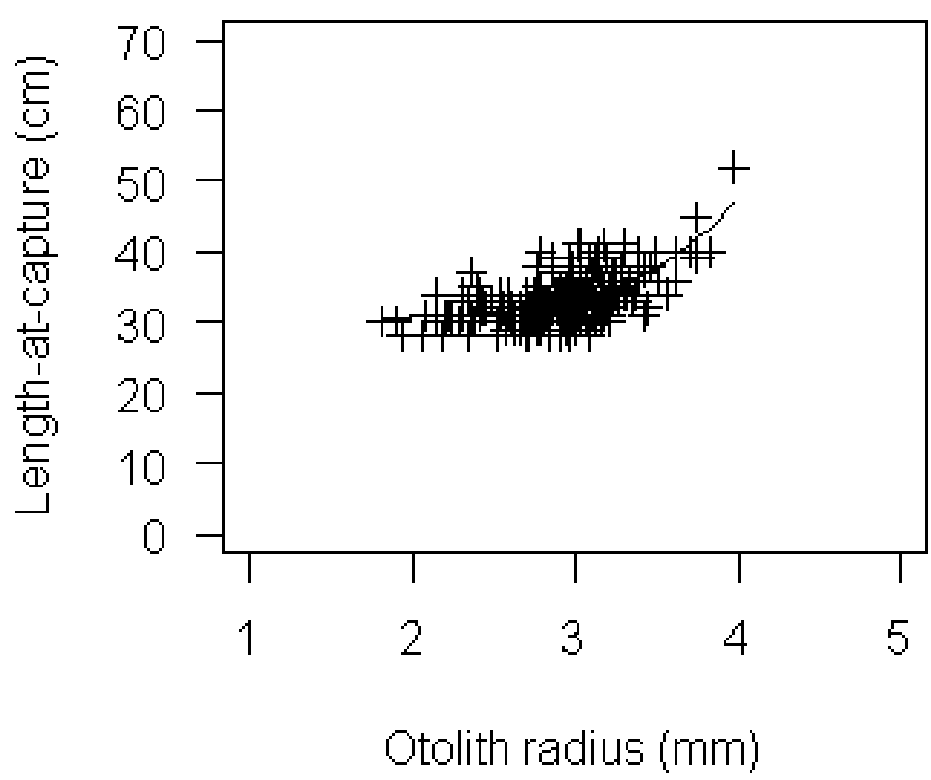

Figure S3. Fish length - otolith radius regression for male whiting, all areas $(\mathrm{n}=266)$. See Table 1 for parameter estimates. 


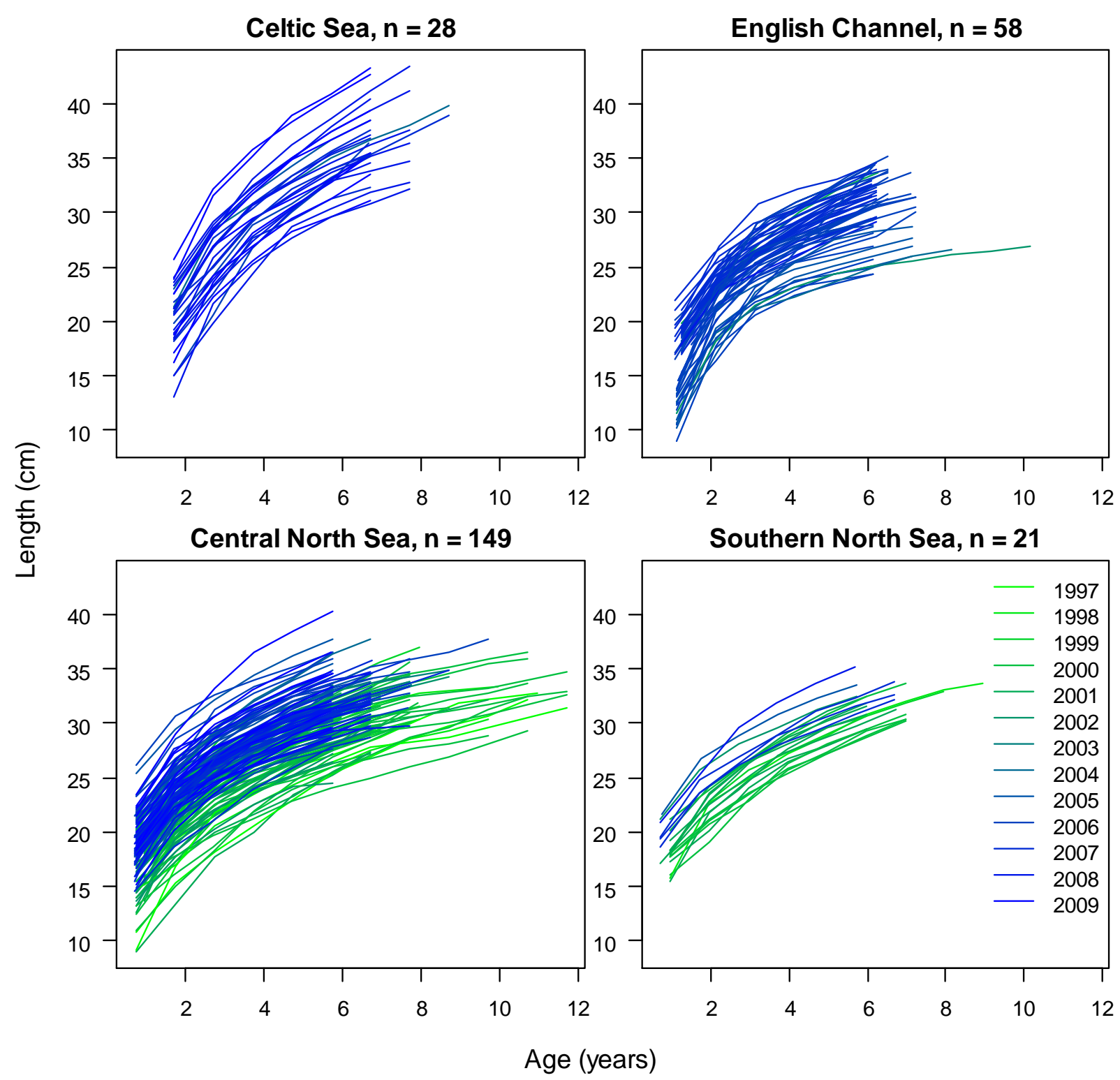

Figure S4. Reconstructed male individual growth trajectories per ICES division. Each cohort is plotted with a different color. 


\section{Male whiting}
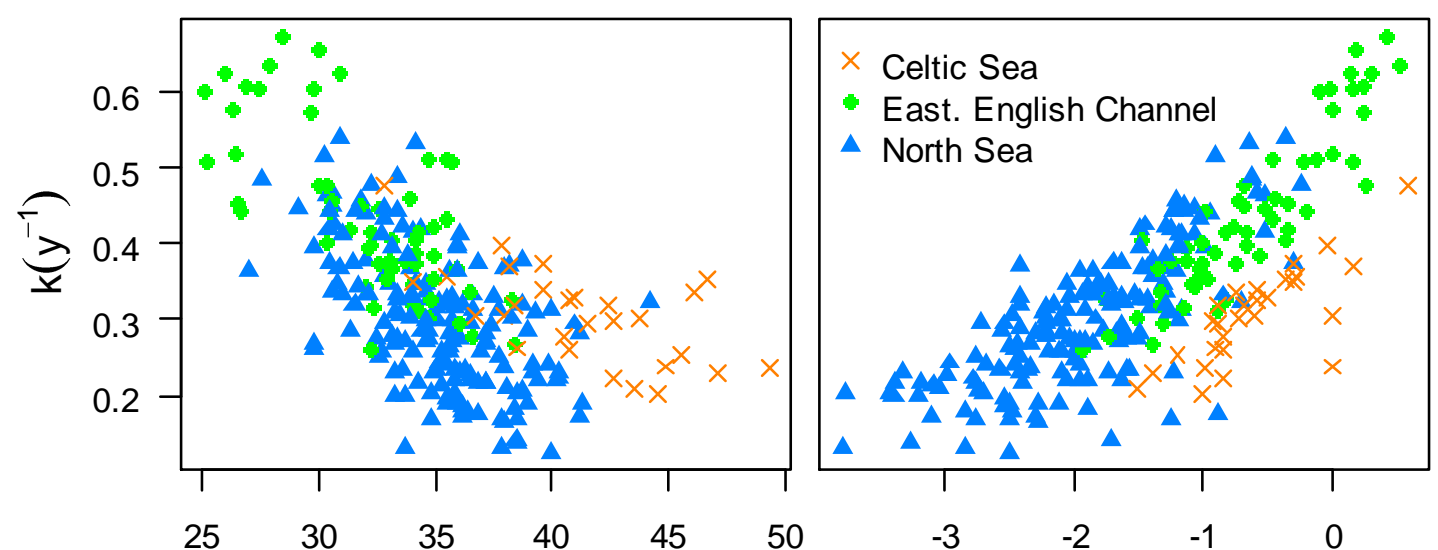

$\mathrm{L}_{\infty}(\mathrm{cm})$

$t_{0}(y)$
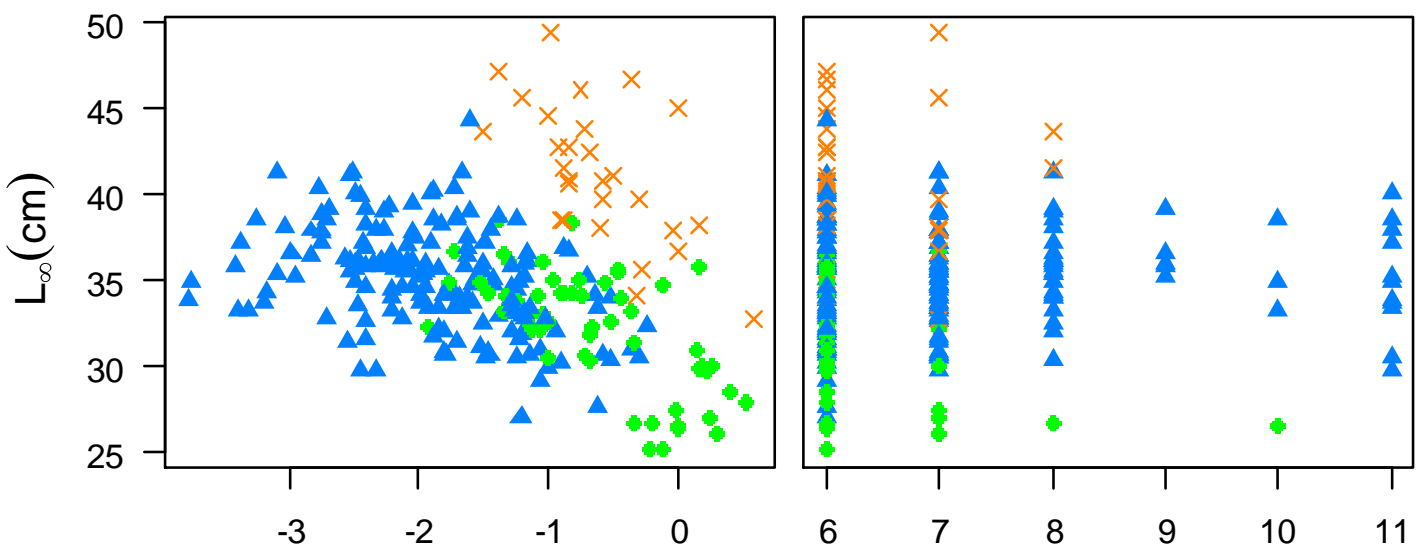

$t_{0}(y)$

Age-at-capture (y)

Figure S5. Estimates of individual growth parameters from the mixed effects model of individual growth trajectories of male whiting. 


\section{Results of reparameterized model}

To avoid correlations between parameter estimates, the Von Bertalanffy growth model can be reparameterized as:

$L_{a}=L_{1}+\left(L_{2}-L_{1}\right) \frac{1-\exp \left(-k\left(a-a_{1}\right)\right)}{1-\exp \left(-k\left(a_{2}-a_{1}\right)\right)}$

(Schnute, 1981)

where $a$ is age, $L_{1}$ and $L_{2}$ are lengths at two selected ages $a_{1}$ and $a 1$, and $k$ is growth rate. Results are shown for individual growth of female whiting in Table S3, with $a_{1}=1 \mathrm{y}$ and $a_{2}=8 \mathrm{y}$.

Table S3. Fixed and random effects estimates for whiting individual parameters of reparameterized model. $L_{1}$ length at age $1, L_{8}$ length at age 8 . Females: 376 individuals, 2610 observations.

\begin{tabular}{lrcc}
\hline & \multicolumn{3}{c}{ Females } \\
\hline Parameter & $L_{1}$ & $L s$ & $k$ \\
\hline Fixed effect & 22.04 & 40.95 & 0.35 \\
$\sigma_{b}$ & 3.35 & 6.64 & 0.06 \\
Correlation with $L_{1}$ & & 0.74 & -0.97 \\
Correlation with $L_{8}$ & & & -0.88 \\
$\sigma_{w}$ & 4.16 & 4.96 & 0.10 \\
Correlation with $L_{1}$ & & 0.68 & -0.22 \\
Correlation with $L s$ & & & -0.18 \\
Residual & & & 0.499 \\
\hline
\end{tabular}

Schnute, J., 1981. A versatile growth model with statistically stable parameters. Can. J. Fish. Aquat. Sci. 38, 1128-1140. 